\title{
Volatile Profile of Sparkling Wines Produced with the Addition of Mannoproteins or Lees before Second Fermentation Performed with Free and Immobilized Yeasts
}

\author{
Gustavo P. Costa, ${ }^{a}$ Karine P. Nicolli, ${ }^{b}$ Juliane E. Welke, ${ }^{a}$ Vitor Manfroi ${ }^{*, a}$ and \\ Claudia A. Zini*,b \\ anstituto de Ciência e Tecnologia de Alimentos, Universidade Federal do Rio Grande do Sul (UFRGS), \\ Av. Bento Gonçalves, 9500, 91501-970 Porto Alegre-RS, Brazil \\ ${ }^{b}$ Instituto de Química, Universidade Federal do Rio Grande do Sul (UFRGS), \\ Av. Bento Gonçalves, 9500, 91501-970 Porto Alegre-RS, Brazil
}

\begin{abstract}
Heat map and hierarchical cluster analysis showed that sparkling wines produced with immobilized yeasts contained mostly higher levels of compounds that impart positive notes to wines. Fisher ratio pointed out nine volatile compounds as the main components responsible for differentiation of samples treated with mannoproteins/lees and others. Principal component analysis (PCA) showed differences between the sparkling wines produced with and without adjuvants (commercial mannoproteins or lees). Sparkling wines aged without adjuvants presented higher levels of decanoic and dodecanoic acids (fatty/metallic aroma), while the use of mannoproteins or lees resulted in higher content of some fruity esters, nerolidol and $\beta$-damascenone. Therefore, the combination of immobilized yeast and aging on mannoproteins or lees seems to be the most promising treatment to obtain the volatile profile that positively influence wine quality.
\end{abstract}

Keywords: sparkling wine, immobilized yeast, traditional method, champenoise, aging, volatile compounds

\section{Introduction}

Sparkling wines produced by the traditional method are prepared through double fermentation followed by aging of the bottled wine in contact with the lees. The first fermentation transforms grape must into base wine, which undergoes alcoholic fermentation in the bottle after the addition of a suspension of yeasts and sugar (liqueur de tirage $).{ }^{1}$ After second alcoholic fermentation, when the atmospheric pressure is greater than $4 \mathrm{~atm}$ at $20{ }^{\circ} \mathrm{C}$ and the alcoholic content is between 10 and $13 \%,{ }^{2}$ the aging on yeast lees from 8 to 24 months takes place. After aging, gravity conveys the lees sediment to the bottle neck. This process, known as remuage, has traditionally been carried out with the bottle on pupitres, by manually turning the bottle around 1/8 of a turn for around 15 days. Bottle inclination is gradually increased until they stay perpendicular to the floor. The elimination of yeast lees (dégorgement) is performed inserting the bottle neck in a calcium chloride or glycol solution to freeze the sediment, which is ejected by the pressure within the bottle. ${ }^{1}$

*e-mail: manfroi@ufrgs.br; cazini@iq.ufrgs.br
Although some wineries use automated systems that simultaneously move all bottles during remuage, this step is laborious and time consuming ( 2 weeks). ${ }^{3}$ Immobilized yeasts have been used to simplify remuage and dégorgement procedures. During second fermentation and aging, the immobilized yeasts remain agglomerated and readily flocculate, unlike free yeasts, which are dispersed in the bottle and sediment slowly. ${ }^{4}$

Despite this advantage of immobilized yeasts compared to free yeasts, wineries have not used that technology, as they are afraid of compromising both yeast autolysis and the release of volatile compounds during autolysis/ aging. One of the risks would be the sorption of volatile compounds on immobilized yeasts during aging due to the higher surface provided with the immobilization process. In this stage, cytoplasmic and cell wall compounds of yeasts are released due to enzymatic action, including mannoproteins. ${ }^{3}$ Mannoproteins may have positive effect mainly on foam stability of sparkling wines ${ }^{5}$ and on aroma of white wines. ${ }^{6}$ Lees recovered from previous Charmat or traditional processes are rich in mannoproteins and may be used during vinification with the purpose of improving wine aroma. A successful recycling of lees 
in the vinification process is an interesting option for wineries, as this solid waste would not be incorrectly disposed in the environment and would add value to the final product. However, there is only one study reported in the literature about the use of such material in sparkling wines production, in which lees recovered from the first fermentation of traditional sparkling wines were included into the liqueur de tirage for the second fermentation of Bombino grapes base wine. ${ }^{7}$ Higher concentration of fruity esters, in particular ethyl hexanoate and ethyl octanoate, besides the improvement in wine complexity (structure, body and aromatic persistence) were the main effects related to this practice.

The addition of commercial products rich in mannoproteins along with the liqueur de tirage to perform the second fermentation and aging of traditional sparkling wines produced with free yeasts has also been proposed to improve the perception of fruity ${ }^{8}$ and floral aroma. ${ }^{9}$ In still wines, the use of free yeast strains with a higher concentration of mannoproteins resulted in higher concentration of positive aroma compounds, such as terpenes and C13-norisoprenoids associated with the fresh, fruity, and floral characteristics of white wines. ${ }^{6}$ Furthermore, mannoproteins added before bottling may be responsible to reduce the undesirable browning of white wines. ${ }^{10}$ They may also delay or prevent tannin polymerization, leading to a reduction of astringency of red wines. ${ }^{11}$ Still in red wines, mannoproteins may improve color stability, structure, roundness and help provide a fullbodied wine when added during fermentation. ${ }^{12}$

Headspace-solid phase microextraction (HS-SPME) and gas chromatography with mass spectrometric detection (GC-MS) are well-established techniques for extraction and determination of volatile compounds of wines, respectively. ${ }^{13-18}$ SPME integrates extraction and concentration into a single solvent-free step, followed by thermal desorption of analytes in the injection port of the GC-MS. Additional advantages of these combined techniques include selectivity, sensitivity, absence of solvent, and the use of small amounts of sample. ${ }^{19}$ Data obtained from different groups of samples may be evaluated using chemometric tools, including cluster analysis. This tool allows displaying subgroups of samples with homogeneous/ similar characteristics; however, it is not possible to visualize which characteristics were responsible for each sub-cluster of samples. A heat map overcomes this drawback since it allows to simultaneously visualize the samples grouping after hierarchical cluster analysis (HCA) and the variables encoded with different colors. High and low data values appear on the heat map with high and low intensity colors, respectively, as for example from red to yellow..$^{20}$ Another chemometric approach that may be used to evaluate volatile profile of sets of samples is the combination of Fisher ratio (FR) and principal component analysis (PCA). ${ }^{15-18} \mathrm{FR}$ is used to determine the features which best describe the data in terms of discriminative power between predefined classes and also to reduce the dimension of the original variables before a multivariate analysis. From the compounds with the highest values of FR, PCA may be used to provide the visualization of the samples and variables in a twodimensional plane organized according to the differences/ similarities between the data. ${ }^{16,18}$

Therefore, the goal of this study was to verify through statistical tools (heat map, HCA, FR and PCA), for the first time, if the use of mannoproteins during autolysis overcomes the drawback that yeast immobilization might cause on volatile profile of sparkling wines obtained by the traditional method. For this purpose, volatile compounds were evaluated in sparkling wines produced with free and immobilized yeasts, in addition to commercial mannoproteins and lees recovered from other sparkling wines previously produced.

\section{Experimental}

\section{Reagents and supplies}

All products used to process base wine were purchased from Amazon Group, Monte Belo do Sul-RS, Brazil, including silica (Solisil 30), gelatin (Lik-gel), Saccharomyces cerevisiae (Maurivin PDM strain), bentonite (Maxibent Plus) and cellulose fibers (Coacel). S. cerevisiae marketed in encapsulated (or immobilized) and free forms were used in this study to perform the second fermentation of the traditional sparkling wine vinification. ProElif $^{\circledast}$ (Proenol, Canelas, Portugal) is a product resulting from immobilization of $S$. cerevisiae in calcium alginate obtained as dehydrated spheres with $2 \mathrm{~mm}$ of diameter. $\mathrm{EC} 1118^{\oplus 21}$ (Proenol) is a free form of S. cerevisiae isolated from the Champagne region and its use has been validated by the Comité Interprofessionnel du Vin de Champagne (CIVC).

A commercial product rich in mannoproteins named Biolees $^{\circledR}$ (Laffort, Bordeaux, France) was evaluated. This preparation of yeast cell walls has a high sapid peptide content and is indicated for fining red wines. ${ }^{22}$

Standard compounds purchased from Aldrich (Steinheim, Germany) included: ethyl hexanoate, ethyl lactate, ethyl octanoate, ethyl decanoate, ethyl dodecanoate, ethyl 9-decenoate, diethyl butanedioate (diethyl succinate), ethyl phenylacetate, isoamyl acetate, 2-phenethyl acetate, hexyl acetate, 1-hexanol, 2-ethyl-1-hexanol, 1-dodecanol, 
2-phenylethanol, hexanoic acid, octanoic acid, nonanoic acid, decanoic acid, dodecanoic acid, $\alpha$-terpineol, linalool, nerolidol and $\beta$-damascenone. The purity of all listed compounds was higher than $98 \%$. Individual stock solutions of each compound $\left(10 \mathrm{mg} \mathrm{L}^{-1}\right)$ were prepared in doubledistilled ethanol purchased from Nuclear (São Paulo-SP, Brazil) and diluted in a wine model solution prepared as previously reported..$^{15}$

The StableFlex SPME fiber $(2 \mathrm{~cm} \times 50 / 30 \mu \mathrm{m}$ divinylbenzene/carboxen/polydimethylsiloxane (DVB/CAR/PDMS)), was purchased from Supelco (Bellefonte, PA, USA) and conditioned according to the manufacturer's recommendations prior to its first use. Sodium chloride $(\mathrm{NaCl})$ of analytical grade was purchased from Nuclear and oven dried at $150{ }^{\circ} \mathrm{C}$ for $2 \mathrm{~h}$ before use. Twenty milliliter headspace vials with Teflon septa were purchased from Supelco.

\section{Production of base wines}

Vitis vinifera grapes of the cultivars Chardonnay, Pinot Noir, Viognier and Riesling were separately vinified (20 kg of each cultivar) in a winery located in Caxias do Sul, Serra Gaúcha region, Brazil. Grapes (18 to 20 Bx) were harvested from three vineyards located in three cities of Serra Gaúcha region: (i) Caxias do Sul (latitude: $29^{\circ} 10^{\prime} 4^{\prime \prime} \mathrm{S}$, longitude: $51^{\circ} 10^{\prime} 46^{\prime \prime} \mathrm{W}$; average altitude of $782 \mathrm{~m}$ ); (ii) Monte Belo do Sul (latitude: 29¹7'29’'S, longitude: 51³9'10”W; average altitude of $438 \mathrm{~m}$ ); and (iii) Nova Prata (latitude: 28 $76^{\prime} 37^{\prime \prime}$, longitude: $51^{\circ} 36^{\prime} 30^{\prime \prime} \mathrm{W}$, average altitude of $699 \mathrm{~m}$ ). Grapes were pressed to obtain the must, which was sulfited with $5 \mathrm{~g} \mathrm{hL}^{-1}$ of $\mathrm{SO}_{2}$ and clarified using silica $\left(40 \mathrm{~g} \mathrm{hL}^{-1}\right)$ and gelatine $\left(4 \mathrm{~g} \mathrm{hL}^{-1}\right)$. S. cerevisiae $\left(20 \mathrm{~g} \mathrm{hL}^{-1}\right)$ was used during the first fermentation in a stainless steel $\operatorname{tank}(25 \mathrm{~L})$ at $15 \pm 2{ }^{\circ} \mathrm{C}$. Malolactic fermentation occurred spontaneously and the conversion of malic acid into lactic acid was monitored through paper chromatography. The stabilization of base wine occurred in cold storage $\left(0{ }^{\circ} \mathrm{C}\right)$ for seven days followed by the clarification with bentonite $\left(40 \mathrm{~g} \mathrm{hL}^{-1}\right)$ and filtration with cellulose fiber.

An assemblage of four grapes cultivars was obtained using 30, 30, 30 and $10 \%$ of Chardonnay, Pinot Noir, Viognier and Riesling base wines, respectively. These cultivars are commonly used by Brazilian wineries to prepare base wines for the elaboration of sparkling wines via traditional method. The physicochemical characteristics of this assemblage were according to limits established by Brazilian law for total acidity ( 55 to 130 mequiv $\left.\mathrm{L}^{-1}\right),{ }^{23}$ total $\mathrm{SO}_{2}$ (maximum of $\left.350 \mathrm{mg} \mathrm{L}^{-1}\right)^{23}$ and alcohol content (8.6 to 14\%), ${ }^{24}$ as shown in Table S1 (Supplementary Information (SI) section).
Immobilization of Saccharomyces cerevisiae used in the second fermentation

The immobilization of $S$. cerevisiae used in the second fermentation was performed according to Callone et al. ${ }^{25}$ with slight modifications and is described as follows. S. cerevisiae (EC1118 ${ }^{\circledR}$; free form) was diluted in distilled water $(1: 10, \mathrm{~m} / \mathrm{v})$ at $25{ }^{\circ} \mathrm{C}$ and sodium alginate $(2 \% \mathrm{~m} / \mathrm{v}$, Cromato, São Paulo-SP, Brazil) was used for the immobilization of the yeast. The solution of sodium alginate $(20 \mathrm{~mL})$ and hydrated yeast $(20 \mathrm{~mL} ; 2 \mathrm{~g}$ of lyophilized yeast was hydrated in $20 \mathrm{~mL}$ of distilled water) was dripped through a stainless steel needle $\left(12.7 \times 0.33 \mathrm{~mm}^{2}\right)$ in $500 \mathrm{~mL}$ of a $0.1 \mathrm{~mol} \mathrm{~L}^{-1}$ calcium chloride solution (Labsynth, São Paulo-SP, Brasil). This was performed by a peristaltic pump (P-1, Pharmacia Biotech, Uppsala, Sweden) with a flow rate of $2.5 \mathrm{~mL} \mathrm{~min}^{-1}$. The Erlenmeyer flask containing the calcium chloride solution was kept on an orbital shaker (Certomat MO, Braun Biotech, Göttingen, Germany) at $60 \mathrm{rpm}$ for $30 \mathrm{~min}$. The immobilized yeast beads were washed four times with distilled water $\left(10^{\circ} \mathrm{C}\right)$ and were stored in sealed polyethylene plastic bags and kept at $4{ }^{\circ} \mathrm{C}$ until use, which occurred in a maximum of $24 \mathrm{~h}$.

\section{Obtaining fine lees from previous sparkling wines production}

Lees $(160 \mathrm{~g})$ recovered from the second fermentation of Charmat and traditional sparkling wines previously produced by the same winery that provided the base wine were centrifuged using $3000 \mathrm{~g}$ of force (4K15, Sigma Laboratory, Osterode am Harz, Germany) for 15 min to separate fine (size $<20 \mu \mathrm{m}$ ) from gross lees. Gross lees comprise grape insoluble compounds, yeast cell mass, precipitated tannins/coloring matter/colloids, and particles formed from fining treatments. Fine lees included essentially dead yeast cells, therefore, rich in mannoproteins, which remain on top of the centrifugation vial (supernatant) and were recovered using a Pasteur pipette.

\section{Second fermentation in bottles and aging on fine lees}

Sucrose (Cristal, Aparecida de Goiânia-GO, Brazil; $\left.30 \mathrm{~g} \mathrm{~L}^{-1}\right)$ and diammonium phosphate $\left(\left(\mathrm{NH}_{4}\right)_{2} \mathrm{HPO}_{4}\right.$; $30 \mathrm{~g} \mathrm{~L}^{-1}$ ) were added to the assemblage base wine. Two types of alcoholic fermentation activators purchased from Laffort were also added to base wine: thiozote $\mathrm{SP}^{\circledR}$ (contains ammonium sulfate, diammonium phosphate and hydrochlorate thiamine) and BioActiv ${ }^{\circledR}$ (formulation based on yeast cellular envelopes (yeast hulls), inert support elements (cellulose), and inactivated yeast for vinification). In addition, a winemaking adjuvant named BioArom ${ }^{\circledR}$ 
(30 $\mathrm{g} \mathrm{hL}^{-1}$; Laffort) was used to prevent oxidation during lees maturation.

Base wines were bottled $(750 \mathrm{~mL})$ and nine types of sparkling wines were produced through the traditional method as detailed in Table 1 . Three forms of S. cerevisae were employed in the second fermentation: experimentally immobilized, commercial immobilized (ProElif ${ }^{\circledR}$ ) and commercial free $\left(\mathrm{EC} 1118^{\circledR}\right)$. The use of commercial mannoproteins and lees obtained from previous Charmat or traditional processes were also evaluated. Sparkling wines were produced in triplicate, totaling 27 bottles.

The type/amount of yeast and winemaking coadjuvant (mannoproteins or fine lees) added in each bottle of the different treatments (T1 to T9) are shown in Table 1. The amount of the commercial yeast (EC1118 ${ }^{\circledR}$ ) used to produce sparkling wines (T5 to T8) followed manufacturer's recommendation. $\mathrm{EC} 1118^{\circledR}(0.15 \mathrm{~g}$ per bottle) was hydrated in $1.5 \mathrm{~mL}$ of distilled water before addition to each bottle of base wine (T5 to T8 samples), and ProElif ${ }^{\circledast}$ ( $0.8 \mathrm{~g}$ per bottle) was used without water dilution in T9. The amount of experimentally immobilized yeast ( $\mathrm{T} 1$ to $\mathrm{T} 4$ ) was higher (5.40 g per bottle) than that of commercial yeast (T5 to T9), since the weight of sodium alginate/calcium chloride and water volume used for the immobilization were also considered, when calculating the mass of the whole mixture added to the bottle $(1.5 \mathrm{~mL}$ of hydrated yeast $+3.9 \mathrm{~g}$ of hydrated calcium alginate). However, the amount of yeast cells was the same for all treatments $\left(10^{10}\right.$ colony forming units (CFU)), regardless of the type of yeast (free or immobilized). The technical data sheet provided by the yeast manufacturer was followed to estimate the amount of CFU based on the dry weight of lyophilized yeast. In the encapsulation procedure, the calcium ion from calcium chloride replaces the sodium of sodium alginate, forming a gelatinous net of the immobilized yeast.

Bottles were closed with metal crown caps and kept in horizontal position for nine months at $20 \pm 2{ }^{\circ} \mathrm{C}$ to allow second fermentation, which was followed by aging on lees. Remuage was carried out with the bottles on a pupitre for 10 days to enable flocculation of free yeasts of the sparkling wines (T5 to T8 samples shown in Table 1). The sedimentation of lees on the neck of sparkling wine bottles occurred immediately after the bottle was turned upside down, for both types of yeasts employed, experimentally immobilized (T1 to $\mathrm{T} 4$ ) and commercial immobilized yeasts (T9). The dégorgement was performed by keeping the bottle in the freezer $\left(-18^{\circ} \mathrm{C}\right)$ for $45 \mathrm{~min}$. In this temperature/time, only the sediment of bottle neck was frozen, allowing the ejection of the sediment by the pressure within the bottle.

\section{Determination of volatile profile}

Samples were degassed in ultrasound (UltraCleaner 1400, Unique, Indaiatuba-SP, Brazil) for 30 min using ice to keep the water bath at $4 \pm 2{ }^{\circ} \mathrm{C}$. Extraction of volatile compounds were performed with HS-SPME, according to a previously optimized method. ${ }^{26}$ In brief, sodium chloride $(0.6 \mathrm{~g})$ was added to $2 \mathrm{~mL}$ of sample placed in $20 \mathrm{~mL}$ glass HS-SPME vials and samples remained for $30 \mathrm{~min}$ at $40^{\circ} \mathrm{C}$ before HS-SPME was carried out without sample agitation.

The analyses of wine volatile compounds were performed using gas chromatography coupled to a quadrupole mass spectrometric detector (GC-qMS) (QP2010, Shimadzu

Table 1. Description of the treatments followed to produce sparkling wines by the traditional method from a base wine made from an assemblage of different grape varieties (Chardonnay 30\%, Pinot Noir 30\%, Viognier 30\% and Riesling 10\% grapes) using free or immobilized yeast and commercial mannoproteins or lees obtained from previous Charmat/traditional processes

\begin{tabular}{|c|c|c|c|c|}
\hline Treatment & S. cerevisae & Amount / (g per bottle $)^{\mathrm{a}}$ & Adjuvant & Amount / (g per bottle $)^{\mathrm{a}}$ \\
\hline $\mathrm{T} 1$ & \multirow{4}{*}{ experimentally immobilized yeasts ${ }^{\mathrm{b}}$} & \multirow{4}{*}{$5.40^{\mathrm{c}}$} & - & - \\
\hline $\mathrm{T} 2$ & & & commercial mannoproteins ${ }^{\mathrm{d}}$ & 0.03 \\
\hline $\mathrm{T} 3$ & & & lees (traditional method) ${ }^{\mathrm{e}}$ & 0.06 \\
\hline $\mathrm{T} 4$ & & & lees (Charmat method) ${ }^{\mathrm{e}}$ & 0.06 \\
\hline T5 & \multirow{4}{*}{ free yeasts (commercial EC1118 ${ }^{\oplus}$ ) } & \multirow{4}{*}{$0.15^{\mathrm{c}}$} & - & - \\
\hline T6 & & & commercial mannoproteins ${ }^{\mathrm{d}}$ & 0.03 \\
\hline $\mathrm{T} 7$ & & & lees (traditional method) ${ }^{\mathrm{e}}$ & 0.06 \\
\hline $\mathrm{T} 8$ & & & lees (Charmat method) ${ }^{\mathrm{e}}$ & 0.06 \\
\hline
\end{tabular}

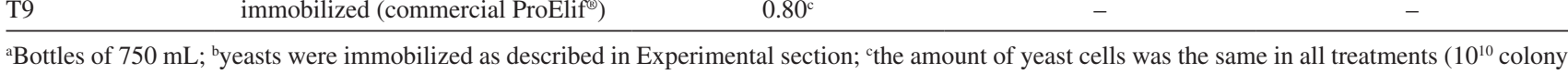
forming units). Treatments T1 to T8 contained $0.15 \mathrm{~g}$ of dry S. cerevisiae that were hydrated with distilled water $(1: 10, \mathrm{~m} / \mathrm{v})$ at $25^{\circ} \mathrm{C}$ for $30 \mathrm{~min}$, totaling $1.5 \mathrm{~mL}$ of hydrated yeast, as recommended in the technical data sheet of $\mathrm{EC} 1118^{\circledR}{ }^{21} \mathrm{~T} 1$ to $\mathrm{T} 4$ also contained $3.9 \mathrm{~g}$ of hydrated calcium alginate; ${ }^{\mathrm{d} B i o l e e} \mathrm{~s}^{\circledR}$ (Laffort); ${ }^{~}$ fine lees recovered from traditional/Charmat sparkling wine previously produced. ProElif ${ }^{\circledR}$ (Proenol) is a product resulting from immobilization of $S$. cerevisiae in calcium alginate obtained as dehydrated spheres with $2 \mathrm{~mm}$ of diameter. 
Scientific Instruments, Kyoto, Japan). Linear temperature programmed retention indices (LTPRI) of volatile compounds were calculated in two different chromatographic stationary phases: a 5\% diphenyl-95\% dimethyl polysiloxane (DB-5) and a polyethylene glycol (DB-Wax). ${ }^{27}$ Area percentage of each volatile compound of base and sparkling wines was calculated considering the sum of chromatographic areas of all detected peaks as $100 \%$, with the exception of the solvent and spurious peaks. Criteria for peak detection were chromatographic area percentage higher than $0.01 \%$ and a minimum spectral similarity of $85 \%$. A compound was considered tentatively identified, if it met the detection criteria and when the difference between the experimentally determined LTPRI and the LTPRI reported in literature was smaller than 19 for polar and non-polar columns. Both columns were purchased from Agilent (J \& W Scientific Inc., Folsom, CA, USA) and their dimensions are as follows: $30 \mathrm{~m} \times 0.25 \mathrm{~mm} \times 0.25 \mu \mathrm{m}$. The oven was kept at $45^{\circ} \mathrm{C}$ for $5 \mathrm{~min}$ and it was heated up to $180^{\circ} \mathrm{C}$ at a rate of $3{ }^{\circ} \mathrm{C} \mathrm{min}{ }^{-1}$, reaching a final temperature of $240{ }^{\circ} \mathrm{C}$ at $20^{\circ} \mathrm{C} \mathrm{min}^{-1}$. Injector and detector temperatures were kept at $250{ }^{\circ} \mathrm{C}$, while helium (analytical purity $99.999 \%$, Linde Gases, Canoas-RS, Brazil) was employed as carrier gas at

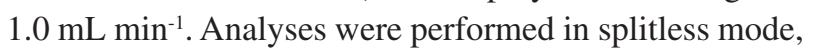
with a liner that is designed for SPME, and purge time of $1 \mathrm{~min}$. The MS parameters included electron ionization at $70 \mathrm{eV}, 1250 \mathrm{~V}$ in the electron multiplier, and a mass range $(\mathrm{m} / \mathrm{z})$ of 45-450 in scan mode.

\section{Chemometric analysis}

Heat map and HCA were performed using XLSTAT201728 (Addinsoft, Paris, France) for Microsoft Excel. FR were calculated according to the approach previously applied by Welke et al. ${ }^{16}$ using Excel software, considering the ratio between the variances of chromatographic area percentages of a compound verified in the different classes of samples and within each class. PCA was performed with the compounds that present the highest FR using the STATISTICA software ${ }^{29}$ (version 7.1, Statsoft, Tulsa, OK, USA).

\section{Results and Discussion}

Thirty-six volatile compounds were identified (24 and 12 compounds were positively and tentatively identified, respectively) in the headspace of base and in the corresponding sparkling wines produced with the addition of mannoproteins or fine lees before second fermentation performed with free or immobilized yeasts. Table 2 shows the LTPRI (experimentally acquired and from literature) obtained in polar and nonpolar chromatographic columns and the odor described in literature for these volatile compounds. In this table, the compounds are separated according to chemical classes and are listed in increasing order of LTPRI of the polar column. Esters were present in higher number (18), followed by higher alcohols (8), fatty acids (4), terpenes (4), C13-norisoprenoid (1) and ketone (1).

Percentage of the chromatographic area of compounds found in each sample analyzed is shown in Table S2 (SI section). These data were obtained with a polar column and were used in the statistical analysis, since the shape of the chromatographic peaks of compounds such as hexanoic acid, 2-phenylethanol and diethyl succinate had the ideal Gaussian shape only in a polar column, as shown in Figure S1a (SI section). In contrast, these peaks presented tail or inadequate shape (Figure S1b, SI section) when a nonpolar column was employed, even with different run temperature programs aiming to achieve a better chromatographic performance (results are not shown regarding different temperature programs).

The heat map (Figure 1) obtained using the percentage of the chromatographic areas of each volatile compound (Table S2, SI section) in base wine and in distinct sparkling wines (T1 to T9, according to Table 1) helps visualization of different contributions of each compound for each sample. According to Figure 1, red, orange and yellow colors represent higher, medium and lower percentage of chromatographic area, respectively.

Six major clusters were responsible for the grouping of volatiles by the HCA (vertical axis). These clusters are indicated as v1 to $\mathrm{v} 6$ from the dashed line of Figure 1. These clusters grouped the compounds that presented higher chromatographic area (represented by red/deep pink color) mainly in the following samples: $\mathrm{T} 1$ to $\mathrm{T} 4$ (cluster v1), $\mathrm{T} 1$ to $\mathrm{T} 7$ (cluster v2), base wine, T2, T4 and T8 (cluster v3), base, T5, T6, T7 and T9 (cluster v4), T5, T8 and T9 (cluster v5), and $\mathrm{T} 5$ to $\mathrm{T} 8$ (cluster v6).

The separation of base wine from the sparkling wine samples (T1 to T9) is clear in Figure 1, as well as the grouping of the sparkling wines produced with experimentally immobilized yeasts ( $\mathrm{T} 1$ to $\mathrm{T} 4$, cluster $\mathrm{s} 1$ in horizontal axis of heat map) from those vinified with free yeasts (T5 to T8, cluster s2 in horizontal axis of heat map). Sparkling wine produced with commercial immobilized S. cerevisiae (T9) was grouped in the cluster of T5 to T8 samples, which were fermented with free commercial yeasts. Therefore, it seems that the use of commercial immobilized or free yeasts did not result in differences in chromatographic volatile profile to a point that could be visualized in Figure 1. 
Table 2. Tentatively and/or positively identified compounds in base wine and in the corresponding sparkling wines produced with the addition of mannoproteins or lees before second fermentation performed with free or immobilized yeasts

\begin{tabular}{|c|c|c|c|c|c|c|c|}
\hline \multirow{2}{*}{ No. } & \multirow{2}{*}{ Compound } & \multirow{2}{*}{ CAS No. } & LTPRI $_{\text {exp }}{ }^{a}$ & LTPRI $_{\text {lit }}{ }^{\mathrm{b}}$ & LTPRI $_{\text {exp }}{ }^{\mathrm{c}}$ & LTPRI $_{\text {lit }}^{\mathrm{d}, 8}$ & \multirow{2}{*}{ Odor $^{e}$} \\
\hline & & & \multicolumn{2}{|c|}{ DB-Wax } & \multicolumn{2}{|c|}{ DB-5 } & \\
\hline \multicolumn{8}{|c|}{ Fatty acids } \\
\hline 1 & hexanoic acid ${ }^{f}$ & $142-62-1$ & 1858 & $1861^{13}$ & 985 & 967 & pungent, rancid, wax ${ }^{18}$ \\
\hline 2 & octanoic acid ${ }^{\mathrm{f}}$ & $124-07-2$ & 2079 & $2086^{13}$ & NF & - & rotten fruit ${ }^{13}$ \\
\hline 3 & decanoic acid ${ }^{\mathrm{f}}$ & $334-48-5$ & 2285 & $2282^{30}$ & 1378 & 1364 & fatty ${ }^{13,30}$ \\
\hline 4 & dodecanoic acid ${ }^{\mathrm{f}}$ & $143-07-7$ & 2496 & $2477^{31}$ & 1564 & 1565 & metallic $^{37}$ \\
\hline \multicolumn{8}{|c|}{ Higher or fusel alcohols } \\
\hline 5 & 1-hexanol ${ }^{\mathrm{f}}$ & $111-27-3$ & 1357 & $1363^{13}$ & 879 & 863 & cut grass, ${ }^{13}$ green grass ${ }^{37}$ \\
\hline 6 & 2-ethyl-1-hexanol ${ }^{\mathrm{f}}$ & $104-76-7$ & 1495 & $1490^{31}$ & 1030 & 1030 & fruity, sweet ${ }^{14}$ \\
\hline 7 & 2-nonanol & $628-99-9$ & 1525 & $1530^{32}$ & 1103 & 1097 & fruity, green ${ }^{37}$ \\
\hline 8 & 2,3-butanediol ${ }^{\mathrm{f}}$ & $513-85-9$ & 1546 & $1545^{13}$ & $780^{\mathrm{g}}$ & 785 & cream, ${ }^{13}$ fruity, flora ${ }^{18}$ \\
\hline 9 & 1-octanol & $111-87-5$ & 1563 & $1563^{13}$ & 1073 & 1063 & fruity, sweet ${ }^{18}$ \\
\hline 10 & 2-phenylethanol ${ }^{\mathrm{f}}$ & $60-12-8$ & 1945 & $1946^{13}$ & 1114 & 1106 & rose,${ }^{13}$ floral $^{18}$ \\
\hline 11 & 1-dodecanol ${ }^{\mathrm{f}}$ & $12-53-8$ & 1972 & $1981^{13}$ & 1476 & 1469 & unpleasant $^{37}$ \\
\hline 12 & tridecanol & $112-70-9$ & NF & - & 1577 & 1575 & NF \\
\hline \multicolumn{8}{|c|}{ Ketones } \\
\hline 13 & 2-nonanone & $821-55-6$ & 1385 & $1386^{31}$ & 1094 & 1087 & fruity ${ }^{38}$ \\
\hline \multicolumn{8}{|c|}{ C13-Norisoprenoids } \\
\hline 14 & $\beta$-damascenone ${ }^{f}$ & $23696-85-7$ & 1830 & $1831^{13}$ & 1387 & 1383 & honey, sweet ${ }^{13}$ \\
\hline \multicolumn{8}{|c|}{ Esters } \\
\hline 15 & isoamyl acetate $^{\mathrm{f}}$ & $123-92-2$ & 1120 & $1125^{13}$ & 884 & 869 & banana $^{13,18}$ \\
\hline 16 & ethyl hexanoate ${ }^{f}$ & $123-66-0$ & 1237 & $1235^{30}$ & 1001 & 997 & fruity, sweet ${ }^{18}$ \\
\hline 17 & isoamyl butyrate & $106-27-4$ & 1268 & $1255^{30}$ & $\mathrm{NF}$ & - & floral, fruity ${ }^{30}$ \\
\hline 18 & hexyl acetate ${ }^{f}$ & $142-92-7$ & 1270 & $1269^{5}$ & 1015 & 1007 & fruity ${ }^{13}$ \\
\hline 19 & ethyl lactate ${ }^{\mathrm{f}}$ & $97-64-3$ & 1340 & $1334^{30}$ & $814^{g}$ & 821 & fruity ${ }^{30}$ \\
\hline 20 & ethyl octanoate ${ }^{f}$ & $106-32-1$ & 1440 & $1444^{6}$ & 1200 & 1196 & ripe fruit, ${ }^{13}$ fruity, ${ }^{30,34}{ }^{\text {sweet }}{ }^{18}$ \\
\hline 21 & ethyl decanoate ${ }^{f}$ & $110-38-3$ & 1644 & $1648^{13}$ & 1398 & 1395 & fruity ${ }^{13}$ grape $^{2}$ \\
\hline 22 & isoamyl octanoate & $2035-99-6$ & 1662 & $1670^{13}$ & 1449 & 1442 & oily ${ }^{13}$ \\
\hline 23 & $\begin{array}{l}\text { diethyl succinate or diethyl } \\
\text { butanedioate }\end{array}$ & $123-25-1$ & 1685 & $1687^{13}$ & 1183 & 1176 & floral, ${ }^{13}$ fruity, sweet ${ }^{30}$ \\
\hline 24 & ethyl 9-decenoate ${ }^{f}$ & $67233-91-4$ & 1694 & $1691^{33}$ & NF & - & $\operatorname{rose}^{13}$ \\
\hline 25 & ethyl phenylacetate ${ }^{\mathrm{f}}$ & $101-97-3$ & 1771 & $1779^{13}$ & 1259 & 1254 & rose, fruity ${ }^{13}$ \\
\hline 26 & 2-phenethyl acetate & $103-45-7$ & 1830 & $1830^{34}$ & 1247 & 1243 & flowery $^{34}$ \\
\hline 27 & ethyl-4-decenoate & $76649-16-6$ & NF & - & 1390 & 1380 & NF \\
\hline 28 & ethyl dodecanoate ${ }^{\mathrm{f}}$ & $106-33-2$ & 1852 & $1856^{13}$ & 1596 & 1594 & sweet, fruity ${ }^{30}$ \\
\hline 29 & methyl tetradecanoate & $124-10-7$ & 2014 & $2009^{33}$ & 1727 & 1722 & waxy $^{39}$ \\
\hline 30 & methyl hexadecanoate & $628-97-7$ & 2206 & $2207^{33}$ & 1928 & 1921 & fruity ${ }^{18}$ \\
\hline 31 & ethyl hexadecanoate & $123-66-0$ & 2285 & $2288^{13}$ & 1995 & 1992 & fruity, apple, wine-like ${ }^{37}$ \\
\hline 32 & methyl linoleate & $112-63-0$ & NF & - & 2103 & 2095 & NF \\
\hline \multicolumn{8}{|c|}{ Terpenes } \\
\hline 33 & linalool $^{\mathrm{f}}$ & $78-70-6$ & 1565 & $1569^{34}$ & 1101 & 1095 & flowery $^{34}$ \\
\hline 34 & nerolidol $^{\mathrm{f}}$ & $40716-66-3$ & 2001 & $1999^{35}$ & 1567 & 1561 & apple, rose ${ }^{39}$ \\
\hline 35 & $\alpha$-terpineol ${ }^{\mathrm{f}}$ & $98-55-5$ & 1699 & $1719^{13}$ & 1189 & 1186 & floral $^{13}$ \\
\hline 36 & geranyl acetone & $689-67-8$ & $\mathrm{NF}$ & - & 1456 & 1453 & NF \\
\hline
\end{tabular}

axperimental retention index (RI) calculated using $n$-alkanes (C8-C24) analyzed in polar (DB-Wax) column of a GC-MS; ${ }^{b}$ literature RI obtained in a polar column: Gürbüz et al. ${ }^{13}$ Fan and Qian, ${ }^{30}$ Umano et al.,${ }^{31}$ Werkhoff et al. ${ }^{32}$ Bosch-Fusté et al. ${ }^{33}$ Escudero et al.,${ }^{34}$ and Zhao et al. $;{ }^{35}$ cexperimental RI calculated using $n$-alkanes (C8-C24) analyzed in nonpolar (DB-5) column of a GC-MS; ${ }^{d}$ literature RI obtained in a nonpolar column as described by Adams; ${ }^{36}$ odor description as reported by Tao and $\mathrm{Li},{ }^{14}$ Nicolli et al.,${ }^{18} \mathrm{Li}$ et al.,${ }^{37}$ Qian and Wang, ${ }^{38} \mathrm{Choi},{ }^{39}$ and Peinado et al. $;{ }^{40}$ f positively identified compounds using standards; ${ }^{\mathrm{L}} \mathrm{LTPRI}$ values were extrapolated from the linear relation between retention times of $n$-alcanes and their predetermined LTPRI. CAS: Chemical Abstracts Service; LTPRI ${ }_{\text {exp }}$ and LTPRI lit: experimental and literature linear temperature programmed retention indices, respectively; DB-Wax: polyethylene

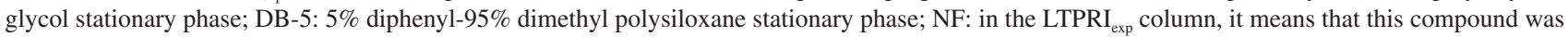
not detected in this specific stationary phase; in the odor column, it means that the odor of this specific compound was not found in scientific literature. 


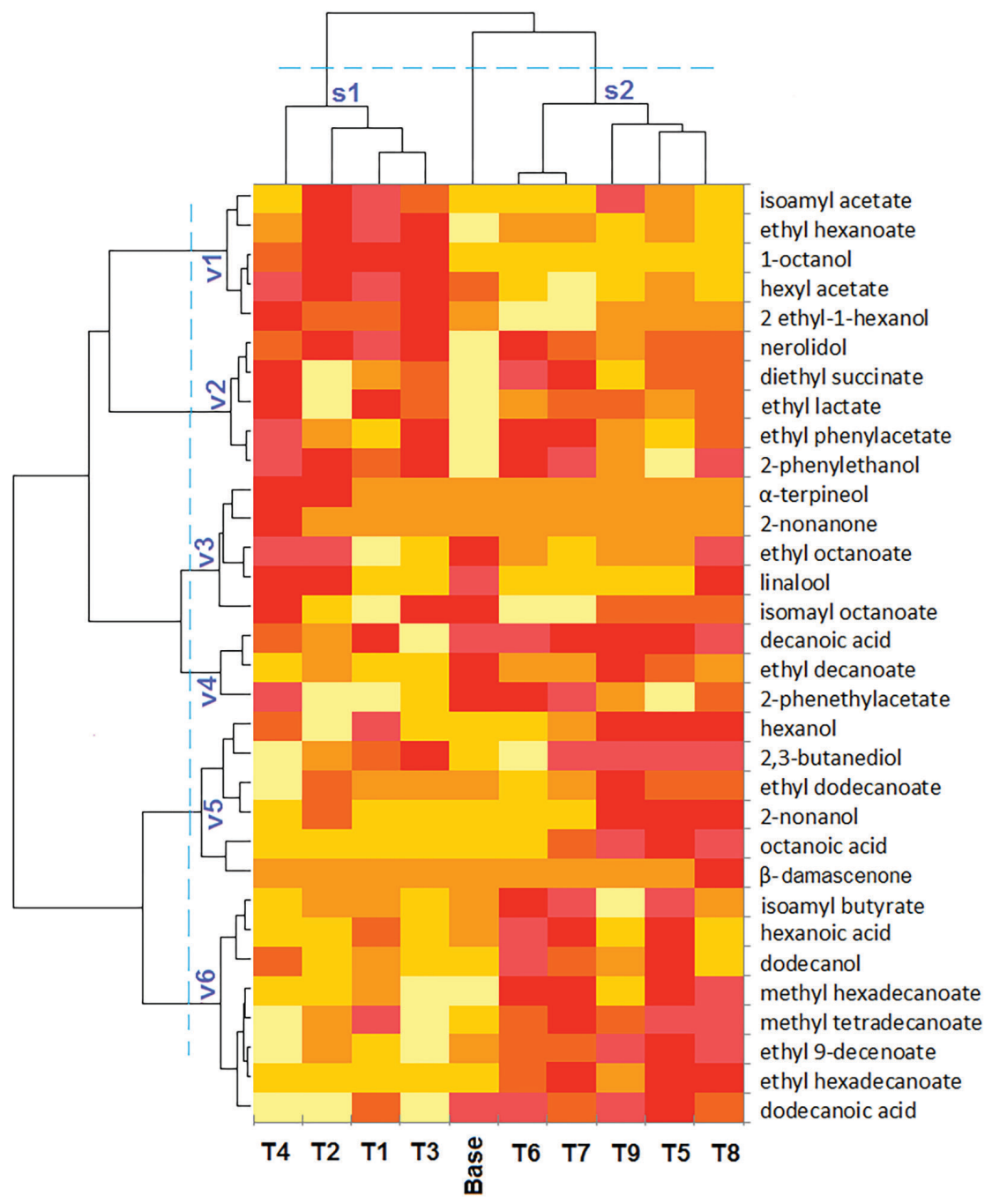

Figure 1. Heat map obtained using the percentage of the chromatographic areas of each volatile compound (Table S2, SI section) in base wine and in distinct sparkling wines (T1 to T9, according to Table 1). Red, orange and yellow colors represent higher, medium and lower percentage of the chromatographic area, respectively. Clusters related to the grouping of volatiles (v) and samples (s) were designated v1 to v6 (vertical axis) and s1 and s2 (horizontal axis) according to the blue dashed line. For interpretation of the references to colors in this figure legend, the reader is referred to the web version of this article. Samples in cluster s1 are the wines produced with experimentally immobilized yeasts (T1 to T4) and the ones in the cluster s2 are the wines vinified with free yeasts (T5 to T8).

Even though an olfactometric analysis would be necessary for a precise definition of the influence of volatile compounds on the aroma, some considerations were done based on literature information. ${ }^{13,34,37}$ In addition, discussions were corroborated by previous study of this research group, ${ }^{18}$ where sensory and GColfactometry were employed to find the possible aromatic contributions of several volatile compounds to different types of wines. This approach provides a simpler and faster data treatment that may render useful results in a preliminary data evaluation and can be of importance especially for quality control of process and products in the sparkling wine industry. ${ }^{16,26}$

Among the clusters of Figure 1, the sparkling wines produced with immobilized yeasts (T1 to T4) may be highlighted because they presented the highest levels of compounds that positively influence the aroma, mainly isoamyl acetate (No. 15, banana) ${ }_{1}^{18}$ ethyl hexanoate (No. 16, fruity/sweet) ${ }^{18}$ 1-octanol (No. 9, fruity/sweet) ${ }^{18}$ hexyl acetate (No. 18, fruity), ${ }^{13}$ and 2-ethyl-1-hexanol (No. 6, fruity/sweet). ${ }^{14}$ The number used in the text references the compounds listed in all tables. Furthermore, all compounds that could impart a negative aroma to base and sparkling wines (see Tables 2 and S2, SI section) were almost always found in lower chromatographic percentages when immobilized yeasts were used (T1 to T4, Figure 1), including hexanoic acid (No. 1, Table 2, pungent/rancid/ wax), ${ }^{18}$ octanoic acid (No. 2, rotten fruit), ${ }^{13}$ decanoic acid (No. 3, fatty), ${ }^{13}$ dodecanoic acid (No. 4, metallic), ${ }^{37}$ 1-hexanol (No. 5, cut grass), ${ }^{13}$ 1-dodecanol (No. 11, 
unpleasant), ${ }^{37}$ isoamyl octanoate (No. 22, oily) ${ }^{13}$ and methyl tetradecanoate (No. 29, waxy). ${ }^{39}$

The use of immobilized yeast may have impaired the amino acid catabolism through the Ehrlich pathway and this might have positively influenced wine quality. Amino acids are initially transaminated to $\alpha$-keto acids, which are decarboxylated, followed by oxidation or reduction reactions resulting in the formation of acids or higher alcohols, respectively. ${ }^{41}$ As mentioned before, a trend for lower levels of all acids was identified in the sparkling wines (Table 2) produced with immobilized yeasts (Figure 1). Additionally, the same trend was observed for two alcohols (hexanol and 1-dodecanol) and two higher molecular weight methyl esters (isoamyl octanoate and methyl tetradecanoate), which are known for negative contribution to odor. These latter compounds were probably enzymatically produced during fermentation through the reaction between an alcohol (ethanol or higher alcohol) and an acid.

FR were calculated taking into account the percentage chromatographic area of the 32 volatile compounds found in base and sparkling wines by GC-qMS using a polar column (Table 2). The compounds with the highest FR were those that contributed the most to differentiate samples according to the presence and contribution of some volatile compounds. Values of FR are shown in Table S2 (SI section). The compounds that presented FR corresponding to at least $15 \%$ of the FR value of the most discriminant compound (2-nonanone, No. 13, FR 331.63) were used in a PCA. This approach has been successfully applied to differentiate Chardonnay sparkling wines, ${ }^{16}$ Moscatel sparkling wines ${ }^{17}$ and Merlot wines produced following different canopy managements ${ }^{18}$ in previous studies. The following volatiles, presented in descending order of FR, were used in the PCA: 2-nonanone (No. 13, FR 331.63), ethyl hexadecanoate (No. 31, FR 120.22), $\beta$-damascenone (No. 14, FR 72.77), ethyl decanoate (No. 21, FR 64.33), methyl hexadecanoate (No. 30, FR 60.90), nerolidol (No. 34, FR 60.00), decanoic acid (No. 3, FR 57.75), dodecanoic acid (No. 4, FR 55.85), and ethyl hexanoate (No. 16, FR 50.44).

The main components (PC) were determined using the Kaiser rule, which selects $\mathrm{PC}$ with eigenvalues greater than one. ${ }^{42}$ The two PC that presented eigenvalues greater than 1 and explained $97.64 \%$ of the variation in the volatile composition of the base and sparkling wines (T1 to T9), are shown in Figure 2.

Table S3 (SI section) shows the eigenvalues, variances and loadings of each variable related to the two PC. The variables with the highest loadings are those that contributed most to explain each PC and were highlighted

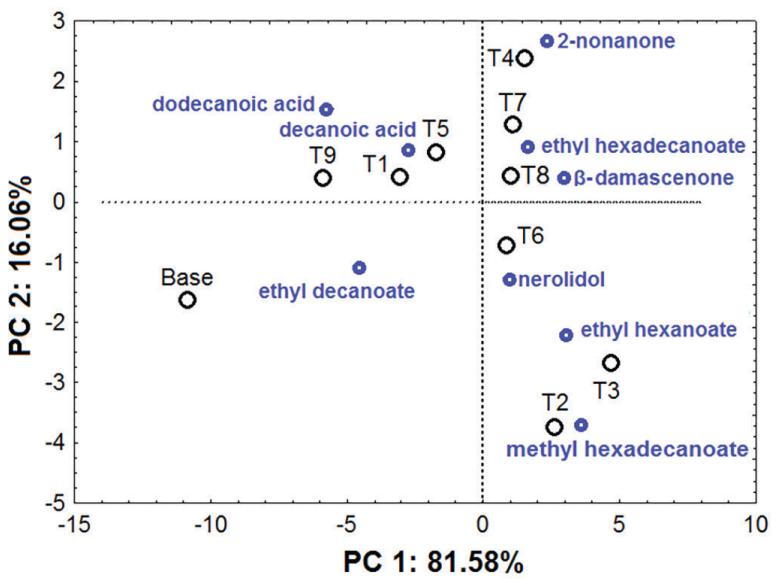

Figure 2. Principal component analysis (PCA) of the nine volatile compounds of the base and sparkling wines (T1 to T9) with the highest Fisher ratios according to Table S2 (SI section).

in bold in Table S3 (SI section). PC1 explains $81.58 \%$ of the data variability and is mainly related to two esters (ethyl hexanoate, No. 16, and ethyl decanoate, No. 21) and to two acids (decanoic, No. 3, and dodecanoic, No. 4). PC2 explains $16.06 \%$ of the data and relates to 2-nonanone (No. 13), ethyl hexadecanoate (No. 31), $\beta$-damascenone (No. 14), nerolidol (No. 34) and methyl hexadecanoate (No. 30). All compounds that are important to locate sparkling wines of T4, T7, T8, T6, T3 and T2 on the right side of the PCA graph impart positive aroma to the wine.

A closer look at the compounds that characterize the samples according to the PCA (Figure 2) shows that ethyl decanoate (No. 21) is the main compound related to base wine. The concentration of this ester (fruity aroma) decreased during the production of the sparkling wines (T1 to T9). This may be visualized in Figure 1 and Table S2 (SI section). Zhang et al. ${ }^{43}$ suggested that the activity of esterases increases during fermentation resulting in the hydrolysis of ethyl decanoate and therefore, decreasing its concentration.

Even though it was not possible to verify the differences/ similarities between the sparkling wines produced without (T1, T5 and T9) or with some adjuvant (T2, T3, T4, T6, T7 and T8), using HCA and the heat map (dealing with all the tentatively identified compounds), the PCA made only with the volatiles with higher FR helped to verify these distinct groups (Figure 2). According to this approach, sparkling wines aged without the use of commercial mannoproteins or lees (T1, T5 and T9) differed from the other samples due to the higher levels of decanoic (No. 3) and dodecanoic acid (No. 4). These acids may compromise the quality of the aroma of the sparkling wines, as they are known for their fatty ${ }^{13}$ and metallic ${ }^{37}$ notes, respectively.

Aging on adjuvants resulted in the presence of compounds that may positively contribute to the wine 
aroma and were found in some particular samples, such as 2-nonanone (No. 13, fruity aroma), which was found only in T4 sparkling wine and $\beta$-damascenone (No. 14, honey/ sweet) detected only in T8 sample. T7 and T8 sparkling wines are located near each other in PCA plot due to the higher levels of ethyl hexadecanoate (No. 31, fruity, apple, wine-like) that was found in higher percentage in these samples. These distinct characteristics shown in PC2 make clear the distinction between samples $\mathrm{T} 4, \mathrm{~T} 7, \mathrm{~T} 8$, and T2, T3 and T6. Samples T2, T3 and T6 are associated with higher levels of nerolidol (No. 34, apple/rose), ethyl hexanoate (No. 16, fruity/sweet) and methyl hexadecanoate (No. 30, fruity), which can positively influence the aroma. The use of mannoproteins and fine lees increased the levels of fruity esters such as ethyl hexanoate (No. 16, fruit/sweet), methyl (No. 30, fruity) and ethyl hexadecanoate (No. 31, fruity, apple, wine-like) probably due to the esterification of fatty acids released by yeasts during fermentation or autolysis.

The presence of 2-nonanone (fruity aroma) may be also attributed to the oxidation of fatty acids. ${ }^{44}$ Pérez-Magariño et al. ${ }^{8}$ have reported that the fruity aroma was better perceived in the sensory analysis of monovarietal sparkling wines Verdejo, Godello, Tempranillo and Garnacha produced with free yeasts and aged with commercial free yeast products rich in mannoproteins, which is in accordance with the results of the present study. Nerolidol (No. 34, T2, T3 and T6) and $\beta$-damascenone (No. 14, T8) released from glycosidic precursors may also be related to the aged sparkling wines on mannoproteins/ lees (T2, T3, T4, T6, T7 and T8). Compounds belonging to these classes (terpenes and $\mathrm{C}-13$ norisoprenoids, respectively) were present in higher concentration in still Albariño wines produced using yeasts containing higher levels of mannoproteins. ${ }^{6}$

\section{Conclusions}

Heat map and HCA helped to show that lower levels of fatty acids that negatively contribute to wine aroma were found in sparkling wines produced with immobilized yeasts (T1 to T4) than those produced using free yeast (T5 to T8). FR calculation followed by PCA revealed that the use of commercial mannoproteins (T2 and T6) or fine lees (T3, $\mathrm{T} 4, \mathrm{~T} 7$ and $\mathrm{T} 8$ ) resulted in higher levels of positive aroma compounds, such as fruity esters. The use of lees recovered from previous Charmat and traditional processes might be a way to take advantage of this material that is discarded by the wineries and can be used to improve the aromatic profile of sparkling wines. Therefore, the combination of immobilized yeast and aging on mannoproteins (T2) or lees
( $\mathrm{T} 3$ and $\mathrm{T} 4$ ) seems to be the most promising treatment to obtain a better quality for volatiles of these sparkling wines.

\section{Supplementary Information}

Supplementary data (physicochemical parameters of base wines, chromatographic data and PCA loadings) are available free of charge at http://jbcs.sbq.org.br as PDF file.

\section{Acknowledgments}

The authors thank Conselho Nacional de Desenvolvimento Científico e Tecnológico (National Council for Scientific and Technological Development, $\mathrm{CNPq}$ ) and Coordenação de Aperfeiçoamento de Pessoal de Nível Superior (Coordination for the Improvement of Higher Education Personnel, CAPES) for the financial support and scholarships. C. A. Zini thanks CNPq for their provision of grant under the project 306067/2016-1 and for the Master's scholarship for Gustavo Costa from PPGCTA-UFRGS.

\section{References}

1. Ribéreau-Gayon, P.; Dubourdieu, D.; Donéche, B.; Lonvaud, A.; Handbook of Enology: The Microbiology of Wine and Vinifications, vol. 1, $2^{\text {nd }}$ ed.; John Wiley \& Sons: Chichester, 2006.

2. Brasil; Decreto No. 8.198 de 20 de fevereiro de 2014. Available at http://www.planalto.gov.br/ccivil_03/_ato2011-2014/2014/ decreto/d8198.htm, accessed in March 2018.

3. Moreno-Arribas, M. V.; Polo, M. C.; Wine Chemistry and Biochemistry; Springer: New York, 2009.

4. Torresi, S.; Frangipane, M. T.; Anelli, G.; Food Chem. 2011, 129, 1232.

5. Martínez-Lapuente, L.; Guadalupe, Z.; Ayestarán, B.; PérezMagariño, S.; Food Chem. 2015, 174, 330.

6. Juega, M.; Nunez, Y. P.; Carrascosa, A. V.; Martinez-Rodriguez, A. J.; J. Food Sci. 2012, 77, 499.

7. la Gatta, B.; Picariello, G.; Rutigliano, M.; Lopriore, G.; Petrella, G.; Rusco, G.; Tremonte, P.; Di Luccia, A.; Eur. Food Res. Technol. 2016, 242, 1307.

8. Pérez-Magariño, S.; Martínez-Lapuente, L.; Bueno-Herrera, M.; Ortega-Heras, M.; Guadalupe, Z.; Ayestarán, B.; J. Agric. Food Chem. 2015, 63, 5670.

9. Rodriguez-Nogales, J. M.; Fernandez-Fernandez, E.; Gomez, M.; Vila-Crespo, J.; J. Food Sci. 2012, 77, 1005.

10. Ribeiro, T.; Fernandes, C.; Nunes, F. M.; Filipe-Ribeiro, L.; Cosme, F.; Food Chem. 2014, 159, 47.

11. Rodrigues, A.; Ricardo-Da-Silva, J. M.; Lucas, C.; Laureano, O.; Food Chem. 2012, 131, 907. 
12. Guadalupe, Z.; Martínez, L.; Ayestarán, B.; Am. J. Enol. Vitic. 2010, 61, 191.

13. Gürbüz, O.; Rouseff, J. M.; Rouseff, R. L.; J. Agric. Food Chem. 2006, 54, 3990.

14. Tao, Y.; Li, H.; Nat. Sci. 2009, 1, 176. DOI: 10.4236/ health.2009.13028.

15. Welke, J. E.; Zanus, M.; Lazzarotto, M.; Zini, C. A.; Food Res. Int. 2014, 59, 85.

16. Welke, J. E.; Zanus, M.; Lazzarotto, M.; Pulgati, F. H.; Zini, C. A.; Food Chem. 2014, 164, 427.

17. Nicolli, K. P.; Welke, J. E.; Closs, M.; Caramão, E. B.; Costa, G.; Manfroi, V.; Zini, C. A.; J. Braz. Chem. Soc. 2015, 26, 1411.

18. Nicolli, K. P.; Biasoto, A. C. T.; Souza-Silva, E. A.; Guerra, C. C.; Santos, H. P.; Welke, J. E.; Zini, C. A.; Food Chem. 2018, $243,103$.

19. Arthur, C.; Pawliszyn, J.; Anal. Chem. 1990, 62, 2145.

20. Sengupta, A.; Advances in Multivariate Statistical Methods, vol. 4; World Scientific Publishing: Singapore, 2009.

21. https://www.proenol.com/web/produtos/levedurasencapsuladas/proelif-1-detail, accessed in March 2018.

22. http://vinestovintages.ca/LaffortTechnicalInfo/PDS_Biolees. pdf, accessed in March 2018.

23. Brasil; Portaria No. 229, de 25 de outubro de 1988. Available at http://www.agricultura.gov.br/assuntos/vigilanciaagropecuaria/ivegetal/bebidas-arquivos/portaria-no-229-de-25de-outubro-de-1988.pdf/view, accessed in March 2018.

24. Brasil; Lei No. 10.970, de 12 de novembro de 2004. Available at http://www.planalto.gov.br/ccivil_03/_ato2004-2006/2004/ lei/110.970.htm, accessed in March 2018.

25. Callone, E.; Campostrini, R.; Carturan, G.; Cavazza, A.; Guzzon, R.; J. Mater. Chem. 2008, 18, 4839.

26. Soares, R. D.; Welke, J. E.; Nicolli, K. P.; Zanus, M.; Caramão, E. B.; Manfroi, V.; Zini, C. A.; Food Chem. 2015, 183, 291.

27. Dettmer-Wilde, K.; Engelwald, W.; Practical Gas Chromatography: A Comprehensive Reference; Springer:
Berlin, 2014.

28. Addinsoft; XLSTAT 2017: Data Analysis and Statistical Solution for Microsoft Excel; Addinsoft, Paris, France, 2017.

29. Statsoft, Inc.; Statistica for Windows, version 7.1; Statsoft Inc., Tulsa, OK, USA, 2005.

30. Fan, W.; Qian, M. C.; J. Agric. Food Chem. 2006, 54, 2695.

31. Umano, K.; Nakahara, K.; Shoji, A.; Shibamoto, T.; J. Agric. Food Chem. 1999, 47, 3702.

32. Werkhoff, P.; Güntert, M.; Krammer, P.; Sommer, M.; Kaulen, J.; J. Agric. Food Chem. 1998, 46, 1076.

33. Bosch-Fusté, J.; Riu-Aumatell, M.; Guadayol, J. M.; Caixach, J.; López-Tamames, E.; Buxaderas, S.; Food Chem. 2007, 105, 428.

34. Escudero, A.; Gogorza, B.; Melús, M. A.; Ortín, N.; Cacho, J.; Ferreira, V.; J. Agric. Food Chem. 2004, 52, 11.

35. Zhao, Y.; Xu, Y.; Li, J.; Fan, W.; Jiang, W.; J. Food. Sci. 2009 , $74,90$.

36. Adams, R. P.; Identification of Essential Oil Component by Gas Chromatography/Mass Spectrometry, $4^{\text {th }}$ ed.; Allured Publishing Corporation: Carol Stream, 2007.

37. Li, H.; Tao, Y.-S.; Wang, H.; Zhang, L.; Eur. Food Res. Technol. 2008, 227, 287.

38. Qian, M.; Wang, Y.; J. Food Sci. 2005, 70, 13.

39. Choi, H. S.; J. Agric. Food Chem. 2003, 51, 2687.

40. Peinado, R. A.; Moreno, J.; Medina, M.; Mauricio, J. C.; Biotechnol. Lett. 2004, 26, 757.

41. Nedović, V.; Gibson, B.; Mantzouridou, T. F.; Bugarski, B.; Djordjević, V.; Kalušević, A.; Paraskevopoulou, A.; Sandell, M.; Šmogrovičová, D.; Yilmaztekin, M.; Yeast 2015, 32, 173.

42. Kaiser, H. F.; Psychometrika 1958, 23, 187.

43. Zhang, M.; Pan, Q.; Yan, G.; Duan, C.; Food Chem. 2011, 125, 743.

44. Pérez-Serradilla, J. A.; Luque de Castro, M. D.; Food Chem. 2008, 111, 447. 